\title{
Pernicious Pregnancy: Type B Aortic Dissection in Pregnant Women
}

\author{
Lara Rimmer ${ }^{1}$, Sophie Mellor ${ }^{2}$, Amer Harky $^{3}$, Mohamed Gouda $^{4}$, and Mohamad Bashir ${ }^{1}$ \\ ${ }^{1}$ East Lancashire Hospitals NHS Trust \\ ${ }^{2}$ University of Birmingham College of Medical and Dental Sciences \\ ${ }^{3}$ Liverpool Heart and Chest Hospital NHS Foundation Trust \\ ${ }^{4}$ Mataria Teaching Hospital
}

August 17, 2020

\begin{abstract}
Type B Aortic Dissection (TBAD) occurs seldomly in pregnancy, but has disastrous consequences for both mother and fetus. The focus of immediate surgical repair of Type A Aortic Dissection due to higher mortality of patients is less clear in its counterpart, TBAD, in which management is controversial and debated. Risk factors for TBAD include: aortic wall stress due to hypertension, previous cardiac surgery, structural abnormalities (bicuspid aortic valve, aortic coarctation), and connective tissue disorders. In pregnancy, pre-eclampsia is a cause of increased aortic wall stress. Management of this condition is often conservative, but this is dependent on a number of factors, including gestation, cardiovascular stability of the patient, and symptomology. In most cases, a Caesarean section prior to intervention is carried out, unless certain indications are present. Due to a scarce number of cases across decades, it is difficult to determine which management is optimal. This article collates knowledge so far on this rare event during pregnancy.
\end{abstract}

\section{Hosted file}

Type B AD in Pregnancy.docx available at https://authorea.com/users/350686/articles/476172pernicious-pregnancy-type-b-aortic-dissection-in-pregnant-women

\section{Hosted file}

Type B AD in Pregnancy Table 1.docx available at https://authorea.com/users/350686/articles/ 476172-pernicious-pregnancy-type-b-aortic-dissection-in-pregnant-women 